\title{
Rossby wave breaking, the upper level jet, and serial clustering of extratropical cyclones in western Europe
}

Article

Published Version

Priestley, M. D. K., Pinto, J. G., Dacre, H. F. and Shaffrey, L. C. (2017) Rossby wave breaking, the upper level jet, and serial clustering of extratropical cyclones in western Europe. Geophysical Research Letters, 44 (1). pp. 514-521. ISSN 0094-8276 doi: https://doi.org/10.1002/2016GL071277 Available at https://centaur.reading.ac.uk/68986/

It is advisable to refer to the publisher's version if you intend to cite from the work. See Guidance on citing.

To link to this article DOI: http://dx.doi.org/10.1002/2016GL071277

Publisher: American Geophysical Union

All outputs in CentAUR are protected by Intellectual Property Rights law, including copyright law. Copyright and IPR is retained by the creators or other copyright holders. Terms and conditions for use of this material are defined in the End User Agreement.

www.reading.ac.uk/centaur 
Central Archive at the University of Reading

Reading's research outputs online 


\section{Geophysical Research Letters}

\section{RESEARCH LETTER \\ 10.1002/2016GL071277 \\ Key Points: \\ Rossby wave breaking, the upper level jet, and serial clustering of extratropical cyclones in western Europe}

- The dynamical patterns associated with clustering changes dependent on clustering location

- RWB anomalies precede jet anomalies by 2 days, acting as a precursor to clustering

- Two-sided RWB is positively correlated with clustering, but there is considerable spread

Supporting Information:

- Supporting Information S1

Correspondence to:

M. D. K. Priestley,

m.d.k.priestley@pgr.reading.ac.uk

\section{Citation:}

Priestley, M. D. K., J. G. Pinto, H. F. Dacre, and L. C. Shaffrey (2017), Rossby wave breaking, the upper level jet, and serial clustering of extratropical cyclones in western Europe, Geophys. Res. Lett., 44, 514-521, doi:10.1002/2016GL071277.

Received 20 SEP 2016 Accepted 28 NOV 2016 Accepted article online 6 DEC 2016 Published online 10 JAN 2017

\author{
Matthew D. K. Priestley ${ }^{1}$ D, Joaquim G. Pinto ${ }^{1,2}$ iD, Helen F. Dacre ${ }^{1}$ iD, and Len C. Shaffrey ${ }^{3}$ (D) \\ ${ }^{1}$ Department of Meteorology, University of Reading, Reading, UK, ${ }^{2}$ Institute for Geophysics and Meteorology, University \\ of Cologne, Cologne, Germany, ${ }^{3}$ NCAS, Department of Meteorology, University of Reading, Reading, UK
}

\section{Introduction}

Intense extratropical cyclones are the primary natural hazard affecting western and central Europe [Della-Marta et al., 2010] and are responsible for 70-85\% of precipitation in these regions [Hawcroft et al., 2012]. Cyclone clustering can lead to greater impacts than those which would have occurred from individual cyclones [Vitolo et al., 2009], since the capacity to respond and the resilience of society is weakened with each subsequent event. Consequently, the clustering of extratropical cyclones is of great interest to insurance industry, civil protection, and policy makers.

Observations suggest that winter 2013/2014 was the stormiest in over 20 years with record-breaking amounts of rainfall (165\% of the UK average) [Matthews et al., 2014; Kendon and McCarthy, 2015]. The season was characterized by clusters of cyclones affecting the UK. Similar behavior has been identified in other winter months (e.g., January 2007) [Pinto et al., 2014]. Previous studies have found that the trajectories of intense North Atlantic cyclones were commonly influenced by Rossby wave breaking (RWB) on both sides of the North Atlantic jet [Hanley and Caballero, 2012; Gómara et al., 2014; Pinto et al., 2014; Messori and Caballero, 2015]. Cyclonic RWB is most commonly found on the northern flank of the jet, with anticyclonic RWB mostly on the southern flank [Nakamura and Plumb, 1994]. Barnes and Hartmann [2012] showed how this presence of RWB acts to flux eddy momentum into the core of the jet, resulting in an acceleration of the upper level flow between these two regions. Large-scale modes of atmospheric variability, such as the NAO (North Atlantic Oscillation) [Hurrell et al., 2003], have also been shown to be related with the clustering of extratropical cyclones [Mailier et al., 2006; Vitolo et al., 2009]. Woollings et al. [2010] found that an NAO+(-) pattern is associated with the jet being in a more northerly (southerly) position, which then controls the location and direction of cyclone tracks over the North Atlantic [Pinto et al., 2009].

Pinto et al. [2014] investigated mechanisms associated with cyclone clustering. They found that clustering events influencing the UK were associated with a zonally extended eddy-driven jet flanked by RWB to the north and south. Clustering can also be influenced by mesoscale processes, for example, Pinto et al. [2014] also highlighted the importance of secondary cyclogenesis during clustering. Secondary cyclones can be very destructive [Dacre and Gray, 2009] and commonly form in trailing cold fronts of extratropical cyclones. However, the development of secondary cyclones is more unpredictable and is influenced by other mechanisms such as the associated deformation strain [Renfrew et al., 1997], frontal shear [Chaboureau and Thorpe, 1999], latent heat release [Joly and Thorpe, 1990], and boundary layer friction [Adamson et al., 2006].

๑2016. American Geophysical Union. All Rights Reserved. 
The aim of this study is to characterize the clustering of extratropical cyclones over the North Atlantic and their relationship with RWB and the upper level jet. We focus on clustering not just for the UK but also at two other regions of Western Europe to the North and South of the UK. Section 3 investigates clustering during winter 2013/2014, while clustering across a 36 year period is investigated in section 4 . Section 5 examines the temporal evolution of RWB and the jet anomalies during clustering, with the variability of RWB and jet examined in section 6 . We will conclude our findings in section 7.

\section{Data and Methods}

In this study, the European Centre for Medium-Range Weather Forecasts Interim Re-Analysis (ERA-Interim) data set [Dee et al., 2011] is used. ERA-Interim has a horizontal resolution of T255 and 60 vertical levels. We use all December-February (DJF) months from 1979/1980 to 2014/2015. To identify extratropical cyclones, the cyclone tracking algorithm of Murray and Simmonds [1991] is applied to ERA-Interim. Cyclones are identified by the Laplacian of mean sea level pressure (MSLP) $\left(\nabla^{2} p\right)$. The nearest MSLP minima is located to the maxima in the $\nabla^{2} p$ field. The tracking algorithm used was adapted for Northern Hemisphere cyclones by Pinto et al. [2005] and performs similarly to other tracking methodologies [Neu et al., 2013]. Following Pinto et al. [2009] cyclones are only selected if they adhere to the following criteria: (1) cyclone lifetime, $\geq 24 \mathrm{~h}$, (2) minimum MSLP $<1000 \mathrm{hPa}$, (3) maximum $\nabla^{2} p>0.6 \mathrm{hPa}$ degree latitude ${ }^{-2}$, and (4) maximum $\frac{\mathrm{d}}{\mathrm{d} t} \nabla^{2} p \geq 0.3 \mathrm{hPa}$ degree latitude ${ }^{-2} \mathrm{~d}^{-1}$.

We follow the definition of Pinto et al. [2014] for cyclone clustering. An area is defined with a $700 \mathrm{~km}$ radius about a latitude-longitude point, and cyclones that adhere to the criteria above and pass through this area are counted. The cyclones are recorded when at peak intensity within this area, with the intensity measured as minimum MSLP. To ensure that only the most intense cyclones are considered, we discard any cyclones with a pressure in the highest $95 \%$ of MSLP climatology at that latitude-longitude point. A day is identified as clustered if the 7 day running sum of the remaining cyclones is greater than or equal to 4 . We perform this analysis for three locations along $5^{\circ} \mathrm{W}$, with the radius centered at $55^{\circ} \mathrm{N}, 5^{\circ} \mathrm{W} ; 45^{\circ} \mathrm{N}, 5^{\circ} \mathrm{W}$; and $65^{\circ} \mathrm{N}, 5^{\circ} \mathrm{W}$ (cf. Figure $\mathrm{S} 1$ in the supporting information), hereafter denominated as $55^{\circ} \mathrm{N} ; 45^{\circ} \mathrm{N}$; and $65^{\circ} \mathrm{N}$. The 95 th percentiles used as an intensity threshold are $999 \mathrm{hPa}$ at $45^{\circ} \mathrm{N}, 984 \mathrm{hPa}$ at $55^{\circ} \mathrm{N}$, and $972 \mathrm{hPa}$ at $65^{\circ} \mathrm{N}$. We have also compared the results of the above method with one based on $850 \mathrm{hPa}$ relative vorticity [Hodges, 1995], with consistent cyclone numbers and clustering periods found across both methods, with the conclusions being unaffected by the method (not shown).

An adapted version of the jet latitude method from Woollings et al. [2010] is used to analyze the behavior of the eddy-driven jet. The original metric uses the daily zonal mean zonal wind at $850 \mathrm{hPa}$ from 25 to $75^{\circ} \mathrm{N}$, 60 to $0^{\circ} \mathrm{W}$. We performed tests for several longitudinal extensions, with each providing consistent results and robust conclusions. However, to focus on the eastern North Atlantic and western Europe, we use $40-0^{\circ} \mathrm{W}$ in our analysis. To generate the anomaly field a long-term daily climatology of the zonal wind is removed with the resulting field being low-pass filtered (Lanczos, 10 day cutoff [Duchon, 1979]) to remove any synoptic influences. The jet latitude on each day is the latitude of maximum wind speed following the removal of the climatology and filtering.

To define and identify RWB, we use the 2-D B index from Masato et al. [2013], which was originally defined by Pelly and Hoskins [2003]. The $B$ index uses the potential temperature $(\theta)$ field on the 2 potential vorticity unit surface (dynamical tropopause; $1 \mathrm{PVU}=1 \times 10^{-6} \mathrm{~K} \mathrm{~m}^{2} \mathrm{~kg}^{-1} \mathrm{~s}^{-1}$ ) which is used as a daily average. The $B$ index is a field that identifies where the meridional gradient of $\theta$ is reversed with positive values indicating the presence of RWB. No persistence criteria is applied in order to identify RWB at each 6-hourly interval. Analysis is also performed on a zonally averaged field; this being from 25 to $75^{\circ} \mathrm{N}, 40$ to $0^{\circ} \mathrm{W}$. As with the eddy-driven jet metric, conclusions were found to be insensitive to the exact choice of longitudinal extent.

\section{RWB and Cyclone Clustering in the Winter of 2013/2014}

The winter season of 2013/2014 was the stormiest on record in the UK [Matthews et al., 2014]. Figure 1a shows the 39 cyclone tracks that passed within $700 \mathrm{~km}$ of $55^{\circ} \mathrm{N}$ throughout January and February 2014; with 26 of these exceeding the local 95th percentile of MSLP. The enhanced cyclone activity is made further apparent when examining the anomaly in cyclone days per month for January and February 2014 (Figure 1b). A statistically significant anomaly of over 12 cyclone days month $^{-1}$ degree latitude ${ }^{-2}$ can be seen near the west coast 

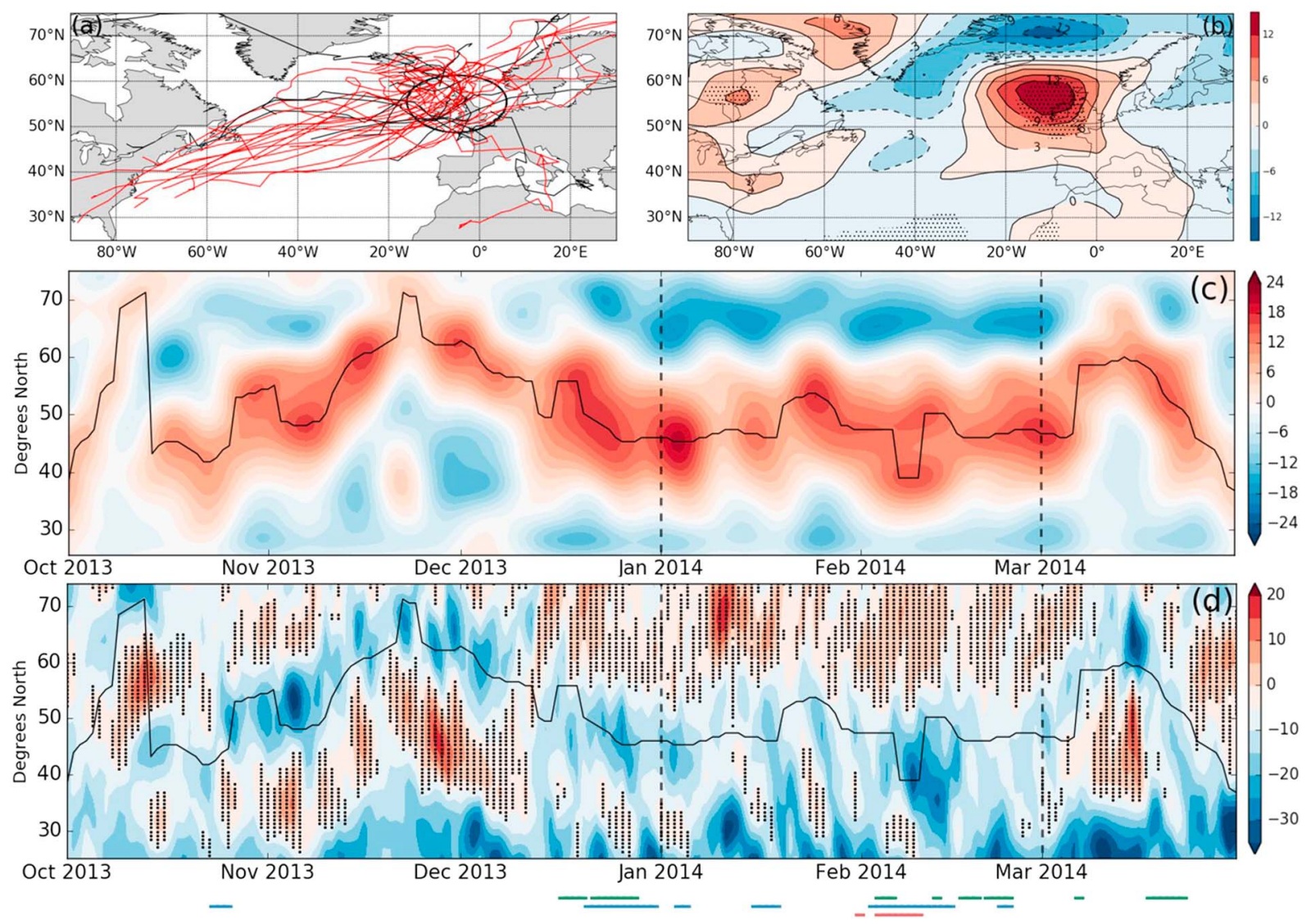

Figure 1. (a) Tracks of cyclones that pass within $700 \mathrm{~km}$ of $55^{\circ} \mathrm{N}$ (black circle) during January and February 2014. Tracks that exceed the 95 th percentile of MSLP are red; others are black. (b) Anomalous track density for January and February of 2014 compared to the climatology. Units are cyclone days month ${ }^{-1}$ degree latitude ${ }^{-2}$. (c) The eddy-driven jet for October to March 2013/2014. Shaded contours are the anomalous wind speeds ( $\mathrm{m} \mathrm{s}^{-1}$ ). The black line represents the jet latitude. (d) RWB in the North Atlantic for October-March 2013/2014. Shaded contours represent the zonally averaged $B$ index on each day; black dots indicate positive values. The black line is the jet latitude. The vertical dashes in Figures $1 \mathrm{c}$ and $1 \mathrm{~d}$ indicate the period used in Figures $1 \mathrm{a}$ and $1 \mathrm{~b}$. The green dashes below the figure indicate clustering for tracks that pass within $700 \mathrm{~km}$ of $65^{\circ} \mathrm{N}$, blue are for $55^{\circ} \mathrm{N}$, and red are for $45^{\circ} \mathrm{N}$ (see Figure $\mathrm{S1}$ ).

of Scotland. A majority of the UK had an increase of at least six cyclone days per month. In this context one cyclone day month ${ }^{-1}$ degree latitude ${ }^{-2}$ corresponds to that latitude square being characterized by cyclonic activity on 1 day of the month.

A number of clustered days are identified for $55^{\circ} \mathrm{N}$ during DJF of 2013/2014. These are 20-30 December; 3-4 and 15-18 January; and 2-14 and 22-23 February. These dates are indicated by the blue dashes below Figure $1 \mathrm{~d}$. Figure $1 \mathrm{c}$ shows that the latitude of the $850 \mathrm{hPa}$ jet varies only a little during January/February 2014, with the latitude being between $40^{\circ} \mathrm{N}$ and $50^{\circ} \mathrm{N}$ on $71 \%$ of days. It is also anomalously strong, with anomalous speeds of $24 \mathrm{~m} \mathrm{~s}^{-1}$ in early January, while for the majority of DJF 2013/2014 speeds are above $10 \mathrm{~m} \mathrm{~s}^{-1}$ greater than the climatology. This is in contrast with late autumn 2013 and early spring 2014, when the jet is weaker and varies more latitudinally.

RWB occurrence over the North Atlantic shows a clear distinction between clustered and non-clustered periods. Clustering at $55^{\circ} \mathrm{N}$ is consistently accompanied by RWB on both the northern and southern flanks of the eddy-driven jet (Figure 1d). RWB to the south is more intermittent (similar to Pinto et al. [2014, Figure 3]), with the RWB to the north being more persistent for much of DJF 2013/2014. The presence of RWB to both the north and the south will act to enhance the thermal gradient in the upper troposphere, allowing for a more intense jet extended toward western Europe. This extension will steer cyclones further toward western Europe, which can cause significant impact and losses if landfall occurs.

We have repeated this analysis for different latitudes. The $700 \mathrm{~km}$ radius was moved both $10^{\circ}$ north and south of $55^{\circ} \mathrm{N}$. The dashes at the bottom of Figure $1 \mathrm{~d}$ show when we identify clustering at $65^{\circ} \mathrm{N}$ (green) and $45^{\circ} \mathrm{N}$ 
(a)

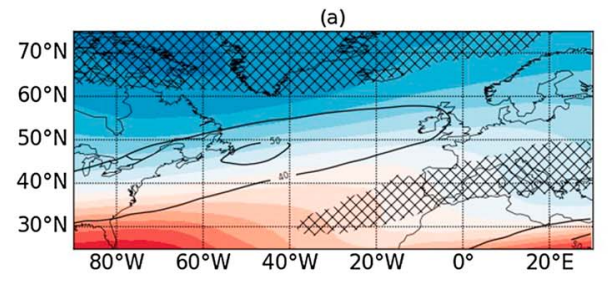

(c)

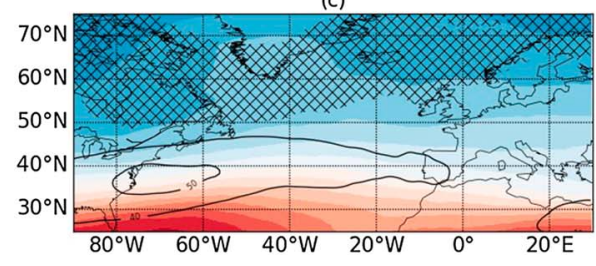

(b)

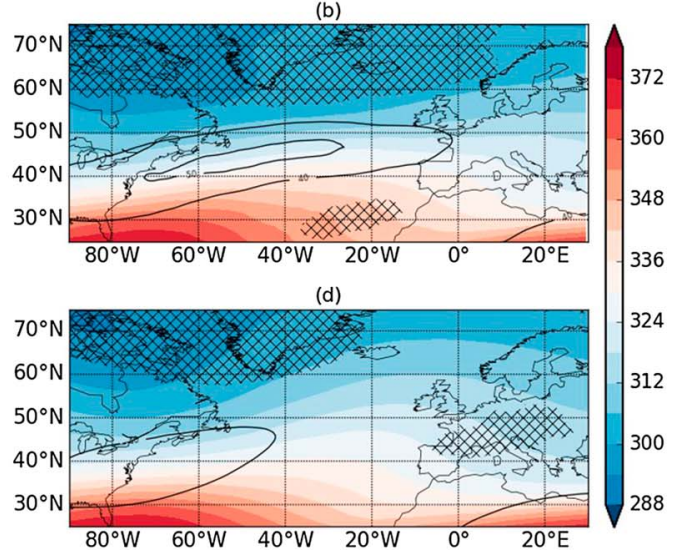

Figure 2. Composites of clustered days at (a) $65^{\circ} \mathrm{N}$, (b) $55^{\circ} \mathrm{N}$, and (c) $45^{\circ} \mathrm{N}$. (d) Climatology. For all panels the colored contours are $\theta$ on the 2 PVU surface (K). Black contours are the $250 \mathrm{hPa}$ wind speed from $40 \mathrm{~m} \mathrm{~s}^{-1}$ and every $10 \mathrm{~m} \mathrm{~s}^{-1}$ above. The crossed hatchings are where RWB was occurring on at least $30 \%$ of days.

(red). The clustering at these latitudes occurs at different times; however, there are some periods of overlap which may be a result of slight overlap of the $700 \mathrm{~km}$ radii (see Figure S1). The green dashes $\left(65^{\circ} \mathrm{N}\right)$ are often associated with the jet in a more northern position (middle of December 2013; early middle of March 2014), and also with a greater presence of RWB to the south (e.g., middle of March 2014). Clustered periods for $45^{\circ} \mathrm{N}$ (red) appear to coincide with the clustering at $55^{\circ} \mathrm{N}$. However, the jet has a very large latitudinal range for the period in early February 2014 , with peak speeds occurring nearer to $40^{\circ} \mathrm{N}$. Hence, the more southerly jet latitude would be steering some of the cyclones further south.

\section{RWB and Cyclone Clustering in ERA-Interim}

The results presented above for 2013/2014 are consistent with findings from Pinto et al. [2014], which were based on the analysis of four other winters. We now extend this analysis to investigate if the dynamical patterns identified for clustering in winter 2013/2014 are valid for all clustered periods in ERA-Interim.

An upper troposphere composite for clustered days ( $\geq 4$ intense cyclones in 7 days) in the DJF season from $1979 / 1980$ to $2014 / 2015$ (387 out of 3240 days) at $55^{\circ} \mathrm{N}$ can be seen in Figure $2 \mathrm{~b}$. It shows an eastward extended and intensified jet that is also straighter than would normally be seen (Figure 2d). This jet is flanked by RWB on both sides, with a sharper thermal gradient between the two regions of RWB than is present in the same region of Figure $2 \mathrm{~d}$. It is apparent from Figure $2 \mathrm{~b}$ that this pattern will cause cyclones that form in the North Atlantic or off the east coast of the USA to be steered eastward along the axis of the jet. This pattern resulted in very stormy conditions at $55^{\circ} \mathrm{N}$, as was seen in winter $2013 / 2014$ and is consistent with that identified in Figure 1 and also the schematic in Figure $7 f$ of Pinto et al. [2014].

The composite image for clustering at $65^{\circ} \mathrm{N}$ (Figure 2a) (450 out of 3240 days) demonstrates a different pattern to that shown in Figure $2 \mathrm{~b}$. For clustering at $65^{\circ} \mathrm{N}$, the jet is much more tilted from $\mathrm{SW}$ to $\mathrm{NE}$, with more RWB to the south and less to the north when compared to Figure $2 \mathrm{~b}$. For clustering at $45^{\circ} \mathrm{N}$ (Figure 2c) (183 out of 3240 days) the jet is zonal until the exit region and is then tilted from NW to SE. Figure $2 \mathrm{c}$ is also characterized by a large amount of RWB to the north, with little RWB to the south. Finally, when days are classed as non-clustered at $55^{\circ} \mathrm{N}$ (Figure S2) (2853 out of 3240 days) the jet is not extended beyond the western North Atlantic and is also weaker than the clustered days. It is characterized by a large area of RWB across western Europe, indicative of anticyclonic blocking, which will steer cyclones to the north or south of western Europe.This is very similar to Figure $2 \mathrm{~d}$ and also the non-clustered composites for $45^{\circ} \mathrm{N}$ and $65^{\circ} \mathrm{N}$ (Figure S2).

Figure 2 shows that clustering at different latitudes is associated with different dynamical patterns in the North Atlantic. The presence of RWB in various locations in the eastern North Atlantic is associated with the tilt and latitudinal location of the jet, and hence, the direction in which the cyclones are steered. This is consistent with findings in previous studies [Benedict et al., 2004; Woollings et al., 2010; Franzke et al., 2011]. 

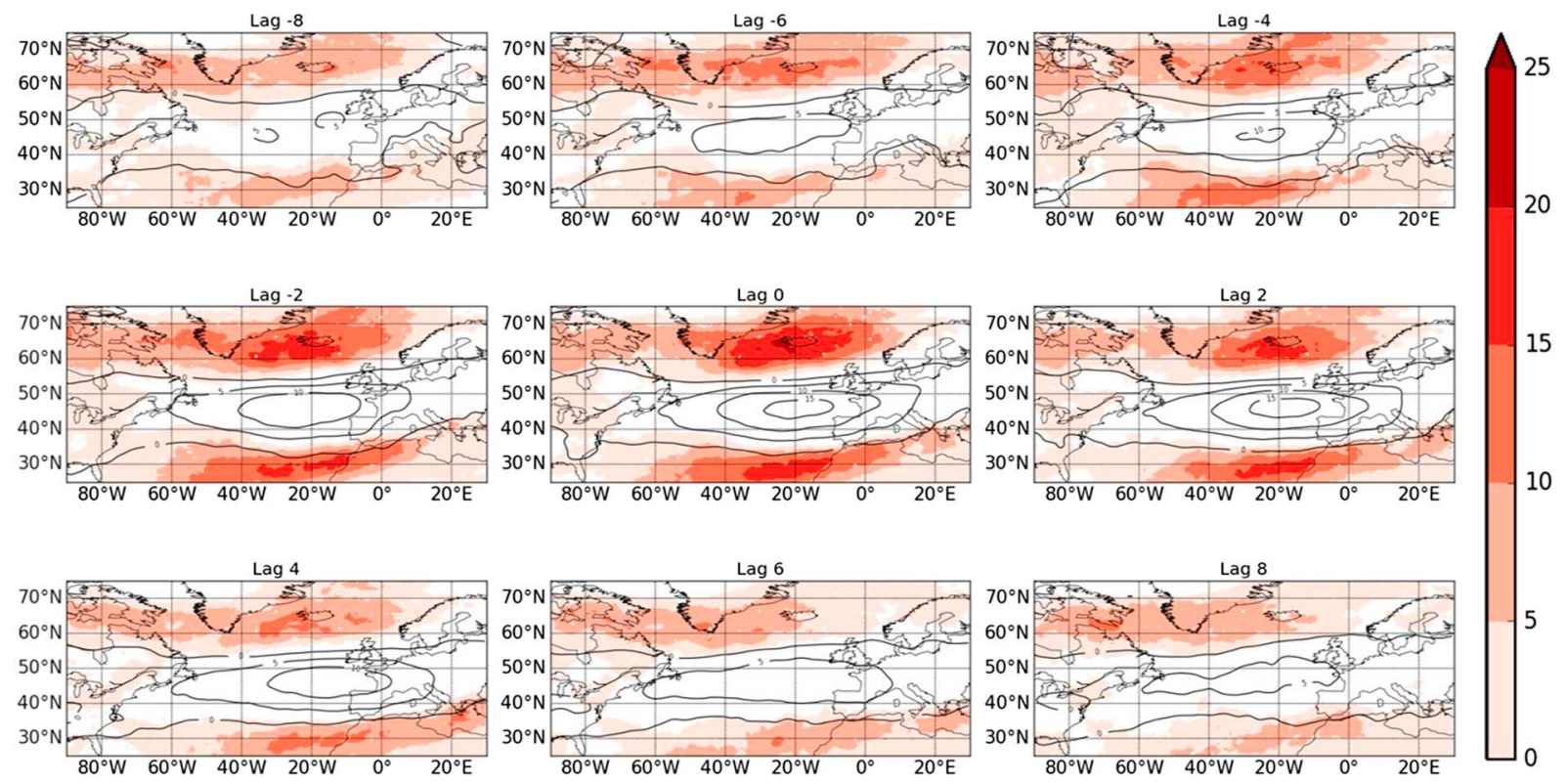

Figure 3. Composite images of North Atlantic RWB and jet anomalies on days lagged to clustered days at $55^{\circ} \mathrm{N}$. The red shading is the percentage increase in the $B$ index compared to climatology (Figure $2 \mathrm{~d}$ ). Black contours are the $250 \mathrm{hPa}$ wind speed anomalies $\left(\mathrm{m} \mathrm{s}^{-1}\right)$. Shown is from lag $-8 \mathrm{days}$ to lag +8 days at 2 day intervals.

\section{The Temporal Evolution of the RWB and the Jet During Clustering}

Figure 3 shows how the RWB and jet anomalies develop in the days before and after clustering at $55^{\circ} \mathrm{N}$. A lagged composite analysis of clustered days further highlights the importance of anomalous RWB in the eastern North Atlantic for clustering. We lag to the clustered days identified for $55^{\circ} \mathrm{N}$ to infer how the dynamical features develop. At lag -8 days jet anomalies are weak, with only isolated regions greater than $5 \mathrm{~m} \mathrm{~s}^{-1}$. The RWB flanking the jet is also similar to climatology (Figure 2d), although some increases of up to $10 \%$ are present in the regions of box a and box c (see Figure S1). At lag -4 days the jet has accelerated further with localized anomalies over $10 \mathrm{~m} \mathrm{~s}^{-1}$ and a further increase in RWB with up to 15\% more RWB in the eastern North Atlantic. RWB activity reaches its maxima at lag -2 days with anomalies of $15-20 \%$ and jet speeds similar to those previously. The jet anomaly peaks on lag 0 days with speeds of more than $15 \mathrm{~m} \mathrm{~s}^{-1}$. Patterns are consistent at lag 2 days; however, by lag 4 days the presence of RWB and the wind speeds begin to decrease. At lag 8 days the presence of RWB in the eastern North Atlantic has almost disappeared, with anomalous wind speeds nearer to $0 \mathrm{~m} \mathrm{~s}^{-1}$. Figure 3 suggests that RWB activity in the eastern North Atlantic peaks before the anomalies in the jet speed. This is consistent with RWB enhancing the upper tropospheric thermal gradient at lag -2 days, which will strengthen wind speeds at $250 \mathrm{hPa}$ and extend the jet eastward; which peaks at lag 0 days. This acceleration can be thought of as a convergence of eddy momentum in the jet core from the RWB on each flank, which is consistent with Barnes and Hartmann [2012].

Similar patterns to Figure 3 are found when we inspect the lagged composite for clustering at $45^{\circ} \mathrm{N}$ and $65^{\circ} \mathrm{N}$ (Figures S3 and S4). In both instances the increases in RWB reaches values of up to $20 \%$ above climatology (Figure $2 \mathrm{~d}$ ) at lag -2 days, which then broaden by lag 0 days and even marginally increase. The RWB in Figure S3 does not peak as clearly at lag -2 days as in Figures 3 and S2. As with Figure 3 both Figures S3 and S4 also see peak wind speeds at lag 0 days.

The composites on lag 0 days also further illustrates the preferential positions of RWB for clustering that can influence western Europe that we identified from Figure 2. Figure 3 suggests that the presence of RWB on one or both sides of the jet is highly important for controlling the strengthening of the upper level jet toward any of our clustering latitudes and hence is a precursor for the observed clustering. This provides a more robust conclusion to the results of Pinto et al. [2014] as analysis was performed using a considerably larger data set. 

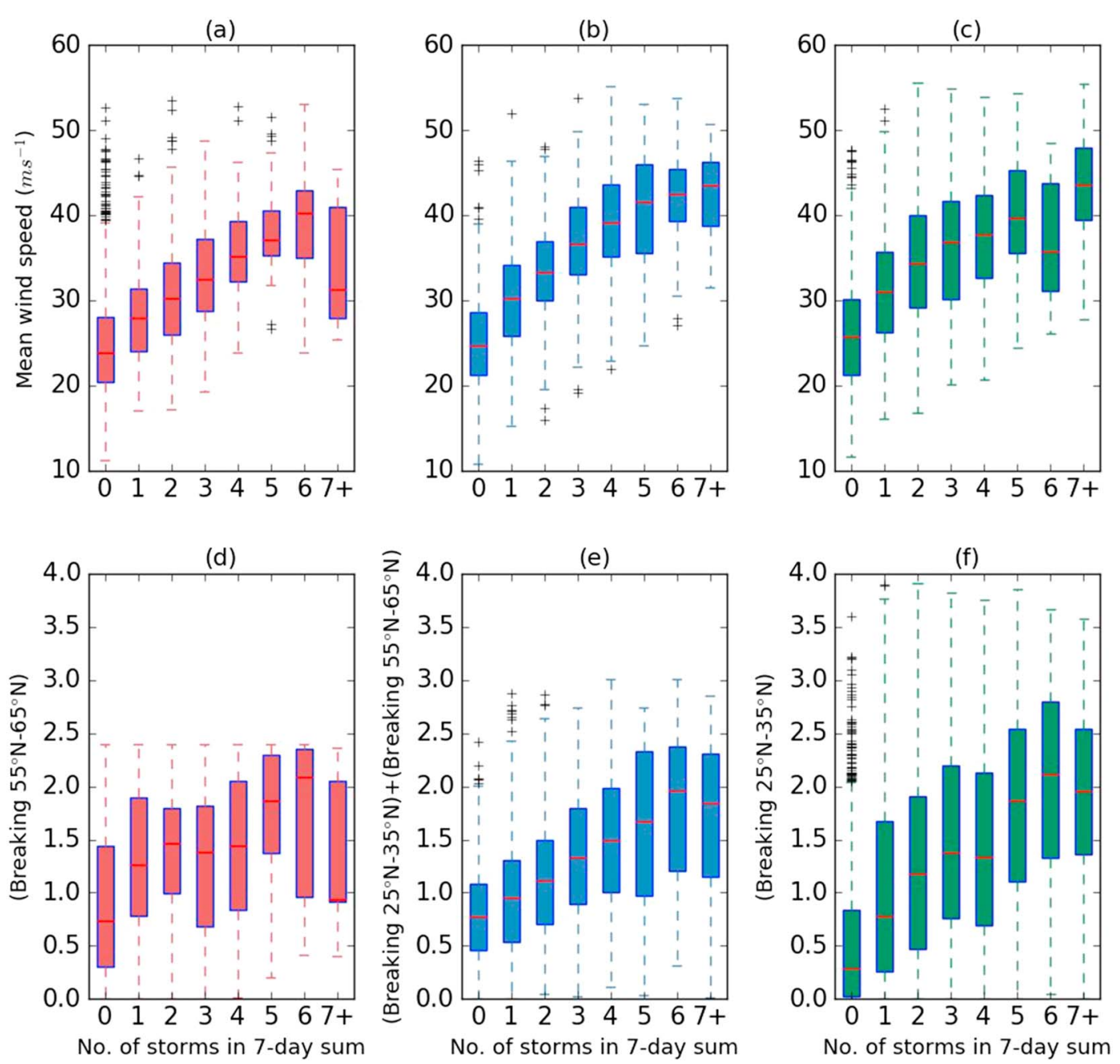

Figure 4. (a-c) Average wind speeds at $250 \mathrm{hPa}$ in box b of Figure $\mathrm{S} 1$ (for $\left.55^{\circ} \mathrm{N}\right) \pm 10^{\circ}$ latitude (for $45^{\circ} \mathrm{N} / 65^{\circ} \mathrm{N}$ ) against the number of cyclones in each days 7 day sum. $(d-f)$ The amount of RWB that takes place in a combination of boxes a and $\mathrm{c}$ in Figure S1. Figures $4 \mathrm{a}$ and $4 \mathrm{~d}$ are for $45^{\circ} \mathrm{N}$. Figures $4 \mathrm{~b}$ and $4 \mathrm{e}$ are for $55^{\circ} \mathrm{N}$. Figures $4 \mathrm{c}$ and $4 \mathrm{f}$ are for $65^{\circ} \mathrm{N}$. The red lines represent the medians, with the edges of the boxes being the upper/lower quartiles. The whiskers extend to either 1.5 times the interquartile range or the value furthest from the median. Crosses are outliers.

\section{Dynamical Variability of Clustering}

Composites such as in Figures 2 and 4 focus on averages. To examine the relationship between the jet and clustering at the different latitudes, we define an area from 40 to $50^{\circ} \mathrm{N}, 30^{\circ} \mathrm{W}$ to $10^{\circ} \mathrm{E}$ (box b in Figure S1; chosen based on examination of Figure 2) and take an average of the $250 \mathrm{hPa}$ wind speed within this. This box is shifted $10^{\circ}$ south(north) for the jet relationship with clustering at $45^{\circ} \mathrm{N}\left(65^{\circ} \mathrm{N}\right.$ ) (a full description of this can be found in the caption of Figure S1).

Figure $4 \mathrm{~b}$ illustrates the relationship between the $250 \mathrm{hPa}$ wind speed and clustering at $55^{\circ} \mathrm{N}$. A positive correlation $(r=0.69)$ is apparent with increasingly clustered activity being associated with stronger $250 \mathrm{hPa}$ wind speeds. Mean $250 \mathrm{hPa}$ wind speeds increase from approximately $25 \mathrm{~m} \mathrm{~s}^{-1}$ on days with no cyclones, to around $40 \mathrm{~m} \mathrm{~s}^{-1}$ for the most clustered days. This is consistent with a stronger and more extended jet directing cyclones eastward across the North Atlantic. There is considerable spread in this relationship (which can be inferred from the size of the box and whiskers in Figure 4b). Consequently, a strong and extended jet may not always be associated with clustered cyclone activity.

The jet relationship for $45^{\circ} \mathrm{N}\left(65^{\circ} \mathrm{N}\right)$ can be seen in Figure $4 a$ (Figure $\left.4 \mathrm{c}\right)$. As in Figure $4 \mathrm{~b}$ a positive correlation is apparent $\left(r=0.45\right.$ for $45^{\circ} \mathrm{N} ; r=0.54$ for $65^{\circ} \mathrm{N}$ (all latitudes are statistically significant)), with days that are 
associated with the clustering of cyclones also being characterized by a stronger and extended jet. However, there is still considerable spread in these relationships, as in Figure $4 \mathrm{~b}$. There is also considerably less cases at the more clustered end of the axis, so this part of the relationship may not be as robust.

The differences in RWB between non-clustered and clustered days is also examined. To achieve this, we define two further areas: the first being from 55 to $65^{\circ} \mathrm{N}, 40$ to $0^{\circ} \mathrm{W}$ (box a in Figure S1) and the second from 25 to $35^{\circ} \mathrm{N}, 40$ to $0^{\circ} \mathrm{W}$ (box c in Figure S1). These boxes were chosen as they capture the areas of RWB to the north and south across all three latitudes (Figure 2). The amount of RWB in each box is calculated by determining the number of latitude-longitude points with a positive $B$ index on each day and then normalizing this relative to climatology. Using this method, a value of 1 relates to a climatological amount of RWB. For clustering at each latitude we take contributions from different boxes based on where RWB is most likely from an examination of Figure 2. For clustering at $45^{\circ} \mathrm{N}$ we use box a, for clustering at $55^{\circ} \mathrm{N}$ we use the average of boxes a and $\mathrm{c}$ after they have been normalized, and finally, for $65^{\circ} \mathrm{N}$ we use only box c.

Figures $4 d-4 f$ suggest that given a large amount of RWB in either box a or box c (or a combination of the two) is associated with an environment that is favorable for clustering, although this is less clear for $45^{\circ} \mathrm{N}$. These preferential locations for RWB have been previously identified to be associated with an enhanced jet and intense cyclones propagating toward western Europe [Gómara et al., 2014; Messori and Caballero, 2015]. This pattern was identified in Pinto et al. [2014], but this is the first time such activity has been linked to all clustering events in a 36 year data set. However, as with the jet (Figures $4 a-4 c$ ) these are dominated by large spread.

It is seen in Figure 4 how the conditions that are favorable for clustering may often be achieved without the presence of multiple cyclones near western Europe. This may be as a result of other properties that are not directly associated with the normal development mechanism of baroclinic instability. For example, the development of secondary cyclones that contribute to clustering have been shown to be dependent on factors such as deformation strain rate, frontal shear, latent heat release, and boundary layer friction. If any of these properties are not favorable for secondary cyclone formation, then this may not result in the presence of the multiple cyclones needed to satisfy our clustering criteria, despite the presence of a favorable large-scale environment. However, this is not investigated in this study.

\section{Conclusions}

The aim of this study is to characterize the clustering of extratropical cyclones over the North Atlantic and their relationship with RWB and the upper level jet. Using the ERA-Interim reanalysis, cyclone clustering in the North Atlantic and its relationship with RWB has been specifically investigated for the winter 2013/2014 and more generally for the winter seasons of 1979/1980-2014/2015. The following are the main conclusions of the study:

1. Cyclone clustering at $55^{\circ} \mathrm{N}$ is associated with an extended and anomalously strong eddy-driven jet flanked on both sides by RWB. However, for clustering at $65^{\circ} \mathrm{N}$ there is a dominance of RWB to the south of the jet, deflecting the jet exit northward and tilting the jet SW-NE tilt. Conversely, for clustering at $45^{\circ} \mathrm{N}$, there is more RWB to the north of the jet, and the jet has a slight NW-SE tilt in its exit, deflecting cyclones further south.

2. RWB activity in the eastern North Atlantic peaks 2 days before the occurrence of clustering and the strongest anomalies in the $250 \mathrm{hPa}$ jet speed. This is consistent with RWB enhancing the upper tropospheric thermal gradient and extending the North Atlantic jet eastward, resulting in cyclone clustering.

3. A positive correlation was identified between the $250 \mathrm{hPa}$ wind in the jet exit and extent of cyclone clustering for 36 winters of ERA-Interim data. A positive correlation was also identified with the RWB when assessing how much RWB was occurring to the north and south of the jet. All latitudes showed an increase in jet speed and RWB activity when there was a greater presence of cyclones. However, there is considerable spread in all of these relationships.

Future research directions include exploring the projected changes in clustering under future climatic conditions in global circulation models [e.g., Economou et al., 2015] and specifically the role of the RWB dynamics we have identified in any potential clustering changes. Additional research directions include exploring the role of secondary cyclogenesis during clustering and the various mesoscale processes that are associated with the development of these cyclones. 


\section{Acknowledgments}

M.D.K.P is funded by NERC via the SCENARIO DTP (NE/L002566/1) and co-sponsored by Aon Benfield. L.C.S is funded by NCAS. We thank ECMWF for their ERA-Interim Reanalysis (http://apps.ecmwf. int/datasets/). All other data are available from the authors (m.d.k.priestley@pgr.reading.ac.uk) Finally, we thank the two anonymous reviewers for their constructive comments that helped to improve this manuscript.

\section{References}

Adamson, D., S. E. Belcher, B. J. Hoskins, and R. S. Plant (2006), Boundary-layer friction in midlatitude cyclones, Q. J. R. Meteorol. Soc., 132(614), $101-124$, doi:10.1256/qj.04.145.

Barnes, E. A., and D. L. Hartmann (2012), Detection of Rossby wave breaking and its response to shifts of the midlatitude jet with climate change, J. Geophys. Res., 117, D09117, doi:10.1029/2012JD017469.

Benedict, J. J., S. Lee, and S. B. Feldstein (2004), Synoptic view of the North Atlantic Oscillation, J. Atmos. Sci., 61(2), 121-144, doi:10.1175/1520-0469(2004)061<0121:SVOTNA>2.0.CO;2.

Chaboureau, J.-P., and A. J. Thorpe (1999), Frontogenesis and the development of secondary wave cyclones in FASTEX, Q. J. R. Meteorol. Soc., 125, 925-940, doi:10.1002/qj.49712555509.

Dacre, H. F., and S. L. Gray (2009), The spatial distribution and evolution characteristics of North Atlantic cyclones, Mon. Weather Rev., 137(1), 99-115, doi:10.1175/2008MWR2491.1.

Dee, D. S., et al. (2011), The ERA-Interim reanalysis: Configuration and performance of the data assimilation system, Q. J. R. Meteorol. Soc., 137(656), 553-597, doi:10.1002/qj.828.

Della-Marta, P. M., M. A. Liniger, C. Appenzeller, D. N. Bresch, P. Köllner-Heck, and V. Muccione (2010), Improved estimates of the European winter windstorm climate and the risk of reinsurance loss using climate model data, J. Appl. Meteorol. Climatol., 49, 2092-2120, doi:10.1175/2010JAMC2133.1.

Duchon, C. E. (1979), Lanczos filtering in one and two dimensions, J. Appl. Meteorol., 18(8), 1016-1022, doi:10.1175/1520-0450(1979)0182.0.CO;2.

Economou, T., D. B. Stephenson, J. G. Pinto, L. C. Shaffrey, and G. Zappa (2015), Serial clustering of extratropical cyclones in a multi model ensemble of historical and future simulations, Q. J. R. Meteorol. Soc., 141(693), 3076-3087, doi:10.1002/qj.2591.

Franzke, C., T. Woollings, and O. Martius (2011), Persistent circulation regimes and preferred regime transitions in the North Atlantic, J. Atmos. Sci., 68(12), 2809-2825, doi:10.1175/JAS-D-11-046.1.

Gómara, I., J. G. Pinto, T. Woollings, G. Masato, P. Zurita-Gotor, and B. Rodríguez-Fonseca (2014), Rossby wave-breaking analysis of explosive cyclones in the Euro-Atlantic sector, Q. J. R. Meteorol. Soc., 140(680), 738-753, doi:10.1002/qj.2190.

Hanley, J., and R. Caballero (2012), The role of large-scale atmospheric flow and Rossby wave breaking in the evolution of extreme windstorms over Europe, Geophys. Res. Lett., 39, L21708, doi:10.1029/2012GL053408.

Hawcroft, M., L. Shaffrey, K. Hodges, and H. Dacre (2012), How much Northern Hemisphere precipitation is associated with extratropical cyclones?, Geophys. Res. Lett., 39, L24809, doi:10.1029/2012GL053866.

Hodges, K. (1995), Feature tracking on the unit sphere, Mon. Weather Rev., 123(12), 3458-3465, doi:10.1175/1520-0493(1995)123<3458:FTOTUS>2.0.CO;2.

Hurrell, J. W., Y. Kushnir, G. Ottersen, and M. Visbeck (2003), An overview of the North Atlantic Oscillation, in The North Atlantic Oscillation: Climatic Significance and Environmental Impact, edited by J. W. Hurrell et al., pp. 1-36, AGU, Washington, D. C.

Joly, A., and A. J. Thorpe (1990), Frontal instability generated by tropospheric potential vorticity anomalies, Q. J. R. Meteorol. Soc., 116(493), 525-560, doi:10.1002/qj.49711649302.

Kendon, M., and M. McCarthy (2015), The UK's wet and stormy winter of 2013/2014, Weather, 70(2), 40-47, doi:10.1002/wea.2465.

Mailier, P. J., D. B. Stephenson, C. A. T. Ferro, and K. I. Hodges (2006), Serial clustering of extratropical cyclones, Mon. Weather Rev., 134(8), 2224-2240, doi:10.1175/MWR3160.1.

Matthews, T., C. Murphy, R. L. Wilby, and S. Harrigan (2014), Stormiest winter on record for Ireland and UK, Nat. Clim. Change, 4(9), 738-740, doi:10.1038/nclimate2336.

Masato, G., B. J. Hoskins, and T. Woollings (2013), Wave-breaking characteristics of Northern Hemisphere winter blocking: A two-dimensional approach, J. Clim., 26(13), 4535-4549, doi:10.1175/JCLI-D-12-00240.1.

Messori, G., and R. Caballero (2015), On double Rossby wave breaking in the North Atlantic, J. Geophys. Res. Atmos., 120, 11,129-11,150, doi:10.1002/2015JD023854.

Murray, R. J., and I. Simmonds (1991), A numerical scheme for tracking cyclone centres from digital data. Part 2: Application to January and July general circulation models, Aust. Meteorol. Mag., 39(3), 167-180.

Nakamura, M., and R. A. Plumb (1994), The effects of flow asymmetry on the direction of Rossby wave breaking, J. Atmos. Sci., 51, 2031-2045, doi:10.1175/1520-0469(1994)051<2031:TEOFAO>2.0.CO;2.

Neu, U., et al. (2013), Imilast: A community effort to intercompare extratropical cyclone detection and tracking algorithms, Bull. Am. Meteorol. Soc., 94(4), 529-547, doi:10.1175/BAMS-D-11-00154.1.

Pelly, J., and B. Hoskins (2003), A new perspective on blocking, J. Atmos. Sci., 60, 743-755, doi:10.1175/1520-0469(2003)060<0743:ANPOB>2.0.CO;2.

Pinto, J. G., T. Spangehl, U. Ulbrich, and P. Speth (2005), Sensitivities of a cyclone detection and tracking algorithm: Individual tracks and climatology, Meteorol. Z., 14(6), 823-838, doi:10.1127/0941-2948/2005/0068.

Pinto, J. G., S. Zacharias, A. H. Fink, G. C. Leckebusch, and U. Ulbrich (2009), Factors contributing to the development of extreme North Atlantic cyclones and their relationship with the NAO, Clim. Dyn., 32(5), 711-737, doi:10.1007/s00382-008-0396-4.

Pinto, J. G., I. Gómara, G. Masato, H. F. Dacre, T. Woollings, and R. Caballero (2014), Large-scale dynamics associated with clustering of extratropical cyclones affecting western Europe, J. Geophys. Res. Atmos., 119, 13,704-13,719, doi:10.1002/2014JD022305.

Renfrew, I. A., A. J. Thorpe, and C. H. Bishop (1997), The role of the environmental flow in the development of secondary frontal cyclones, Q. J. R. Meteorol. Soc., 123(542), 1653-1675, doi:10.1002/qj.49712354210.

Vitolo, R., D. B. Stephenson, L. M. Cook, and K. Mitchell-Wallace (2009), Serial clustering of intense European storms, Meteorol. Z., 18(4), 411-424, doi:10.1127/0941-2948/2009/0393.

Woollings, T., A. Hannachi, and B. Hoskins (2010), Variability of the North Atlantic eddy-driven jet stream, Q. J. R. Meteorol. Soc., 136(649), 856-868, doi:10.1002/qj.625. 